\title{
ONLINE Auction System
}

\author{
S.Kokila ${ }^{1}$ and J.AbalinLuther ${ }^{2}$ T.Marivijayakumar ${ }^{3}$ \\ ${ }^{1}$ Department of Computer Application, Francis Xavier Engineering College \\ ${ }^{2}$ AP Department of Computer Application, Francis Xavier Engineering \\ College
}

${ }^{3}$ Department of Computer Application, Francis Xavier Engineering College

\begin{abstract}
Online auctions are now an immensely popular component of the electronic marketplace. Online Auction management system is a web based application which will help users to buy or sell item.This application will allow users to post their products for auction; bidder can register and can bid for any available product around their location.It is developed with the objective of making the system reliable, easier and fast and to sell or order the products on the website from our house.The online auction system is based on the concept where a product is valued for the highest price.In most online auctions, the products listed for an auction are located away from the bidders location.In our auction system, the bidders or buyers can view the products in auction process which is located around his surroundings. So that the bidder or buyer can participate in auction for his nearby products.
\end{abstract}

\section{KEYWORDS}

Online auction; reliable; highest price; nearby products; bid.

\section{INTRODUCTION}

The internet has become a very important aspect of life today. The rate at which this large population is seeking to buy items is also on the rise, as many people are seeking advanced and ideal routes of trading services. Some people spend a lot of money on transportation, using a lot of time of which at the end of the road they might lack to get the desired items which they opted for. It is open that most of the people are seeking to buy items every day in most cities and towns, both locally and abroad, desperate if they might get a solution or a right person to deliver a solution to them. These people end up settling at items or service providers who are fraud or who sell illegal and fake items to the desperate buyers.

There are legit business people and store owners who have quality items in the locality of the auctioneer, but they do not meet for business because the auctioneer is not informed about the items available. This is a great frustration in deed! This project shall handle this issue by creating an online platform where a user will be able to post items online for auction. The items will accompany item name, selling price, and a picture presentation for the bidder to see. The bidder, if interested in the item, will make the auction for the product and will be able to inspect the item physically to make an approvement about the product then complete the business with the seller. People are always on the go to their renown product supplier, or nearby market center or at times a local hawkers, who goes on to supply items and at times when he cannot get the item the buyer wants, mostly they give their hands to get them items and at times they mess and bring fake and quarks deliver stolen and bad items. This is because unqualified people offer 
delivery of items to customers. Due to the disparity of the buyers, scammers have always taken the advantage to offer item delivery to the customers. Many fake items have found their way into the hands of the people, or buyers remain in the same condition of lack, as they don't get the correct products from the sellers. Sometimes buyers struggle to find the right items, in failure, and they seek to get back to their homes.[4] The customers will be assured of getting the right products, since they will take their time to analyses and compare a range of listed items and choose appropriately according to their need or desire.This will save time that buyers take in search of items and therefore they will save themselves from worsening of conditions which may lead to wastage of time conditions. This will also save money that is spend around travelling and bidding for the undesired items.

\section{Problem Statements}

\section{A. Existing System}

The process of an online auction is much the sameas a live auction. This means that users place bidsfor items, and the goods get sold to the highest bidder.

In existing online auction systems, they allow users for bidding but the product is not available in bidder's local area.Then, in most online auctions they get the card details during bidding process which leads to privacy issues.

\section{B. Proposed System}

This online auction system lists the products to the registered users according to his location and so the bidders can bid to his nearby available products. The card details is asked only to the users whohave won the auction process.

\section{Architectural Diagram}

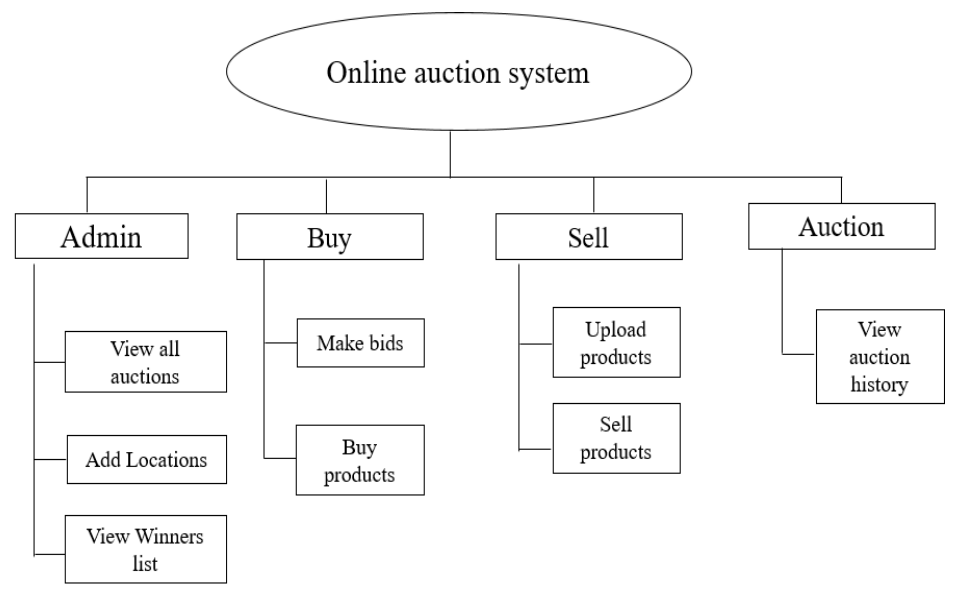

Figure-1 Architecture Diagram 


\section{EXPERIMENTS AND RESULTS}

\section{Module}

\section{A. Admin}

This module was build to manage the auction process, user details and acts as a admin interface. Admin is capable of adding new location into the portal so that all the registered users can make use of the location.Sellers can sale products in that location and the bidders can select the location and make bids.The overall auction process is maintained by the admin. The registered users list can be viewed by the admin.

\section{B. Bid}

This module allows the bidders to make bid for any product.A registered bidder logs into the system and select the curent location. All the products under the selected location is shown and then the bidder can make bid for any interested product.After the auction ends, the bidder is capable of viewing the bidding status whether the auction of that product has been won or lost.

\section{C.Sell}

This module is used by the sellers to sell their products in auction. The seller uploads the product in their current location.Seller can view all the bids that has been made for isproducts. Then seller accepts the highest bidder and rejects other bidders.

\section{Auction}

This module enables bidders about their auction history and bidding status of auctioned products. The sellers finalize the auction status for their own products according to the amount bided by bidders. The highest bidder is accepted and others are rejected in this module.

\section{PERFORMANCE ANALYSIS}

The Existing and proposed system are analysed. In existing online auction systems, they allow users for bidding but the product is not available in bidder's local area. This online auction system lists the products to the registered users according to his location and so the bidders can bid to his nearby available products.Nearly $70 \%$ performance has been increased 


\section{Output Screen}

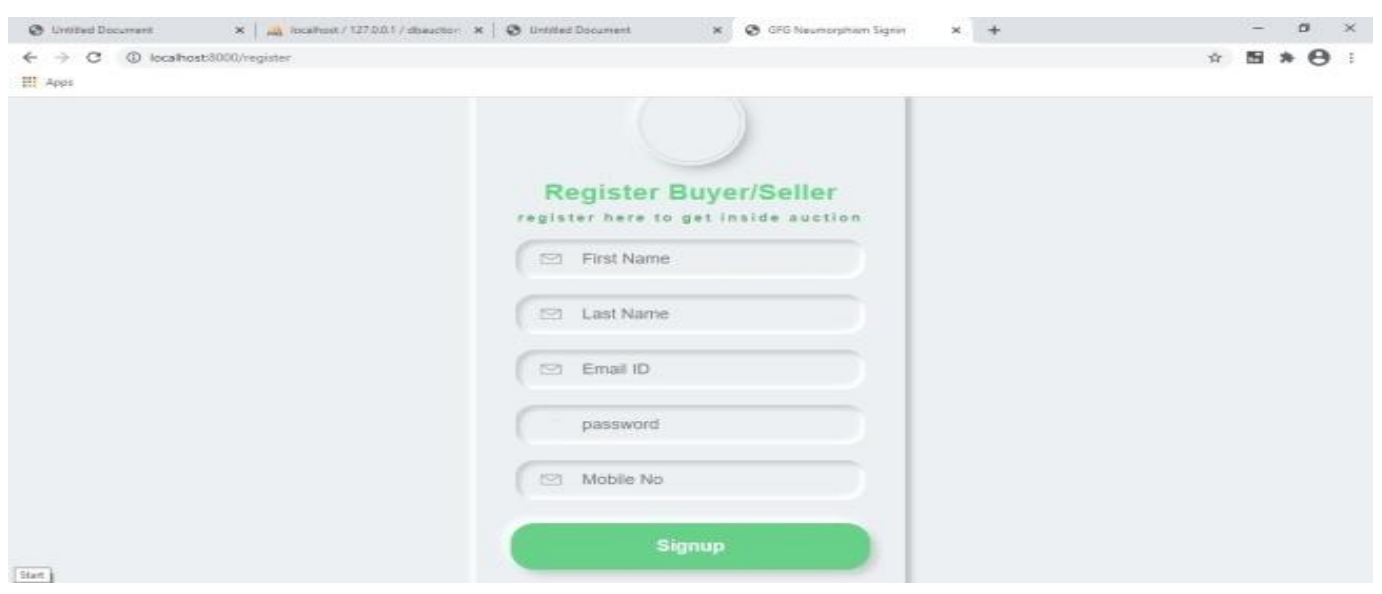

Figure-2 Registration

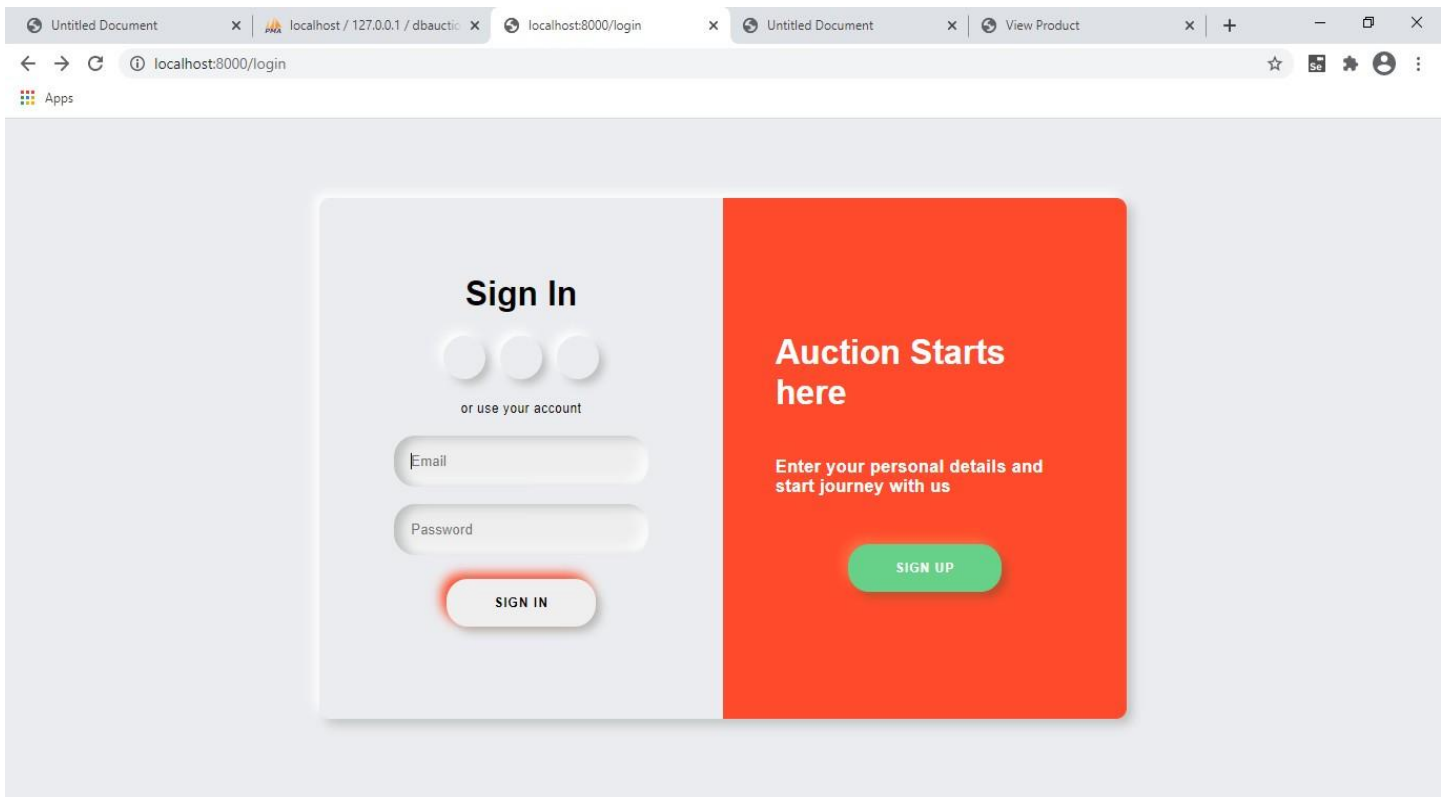

Figure-3 Login 


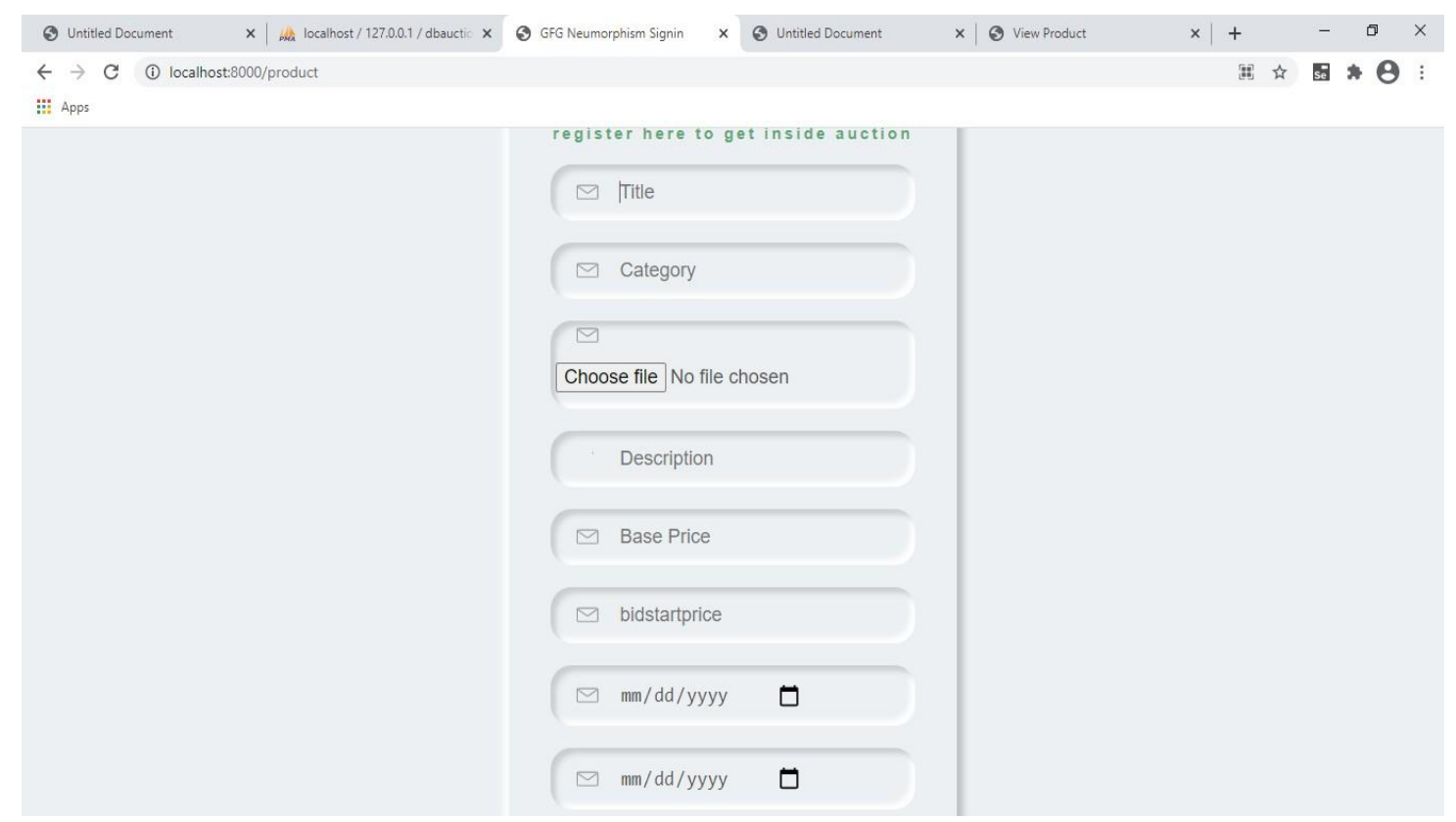

Figure-4 SellProduct

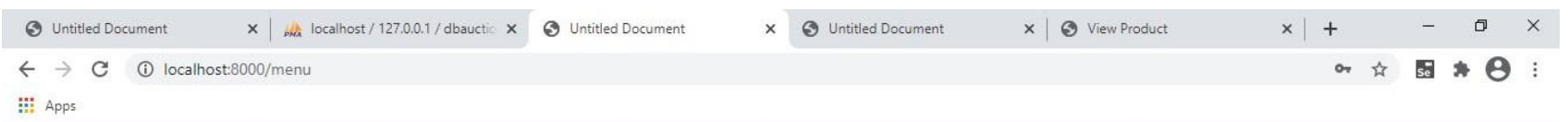

::: Apps

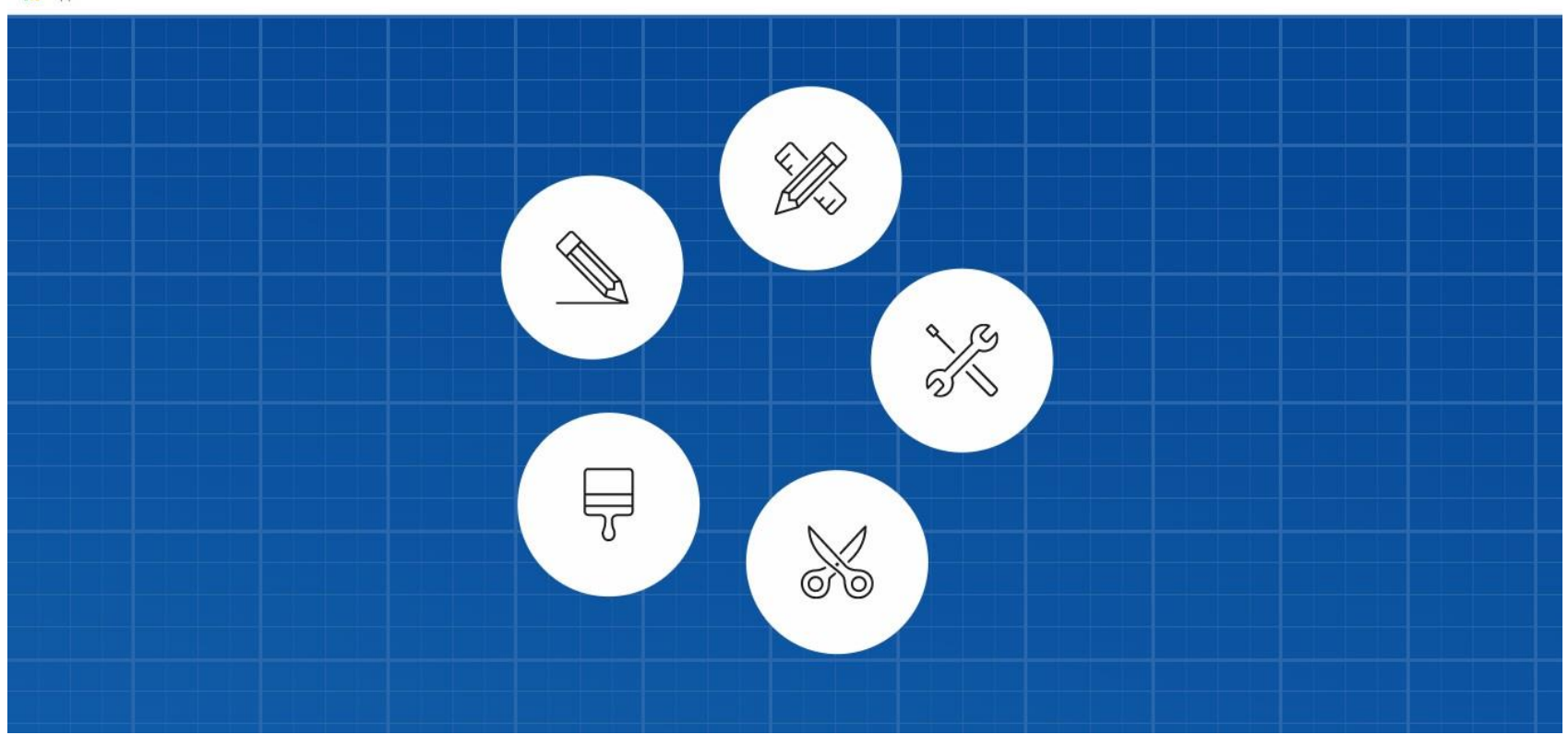

Figure-5 Menu 


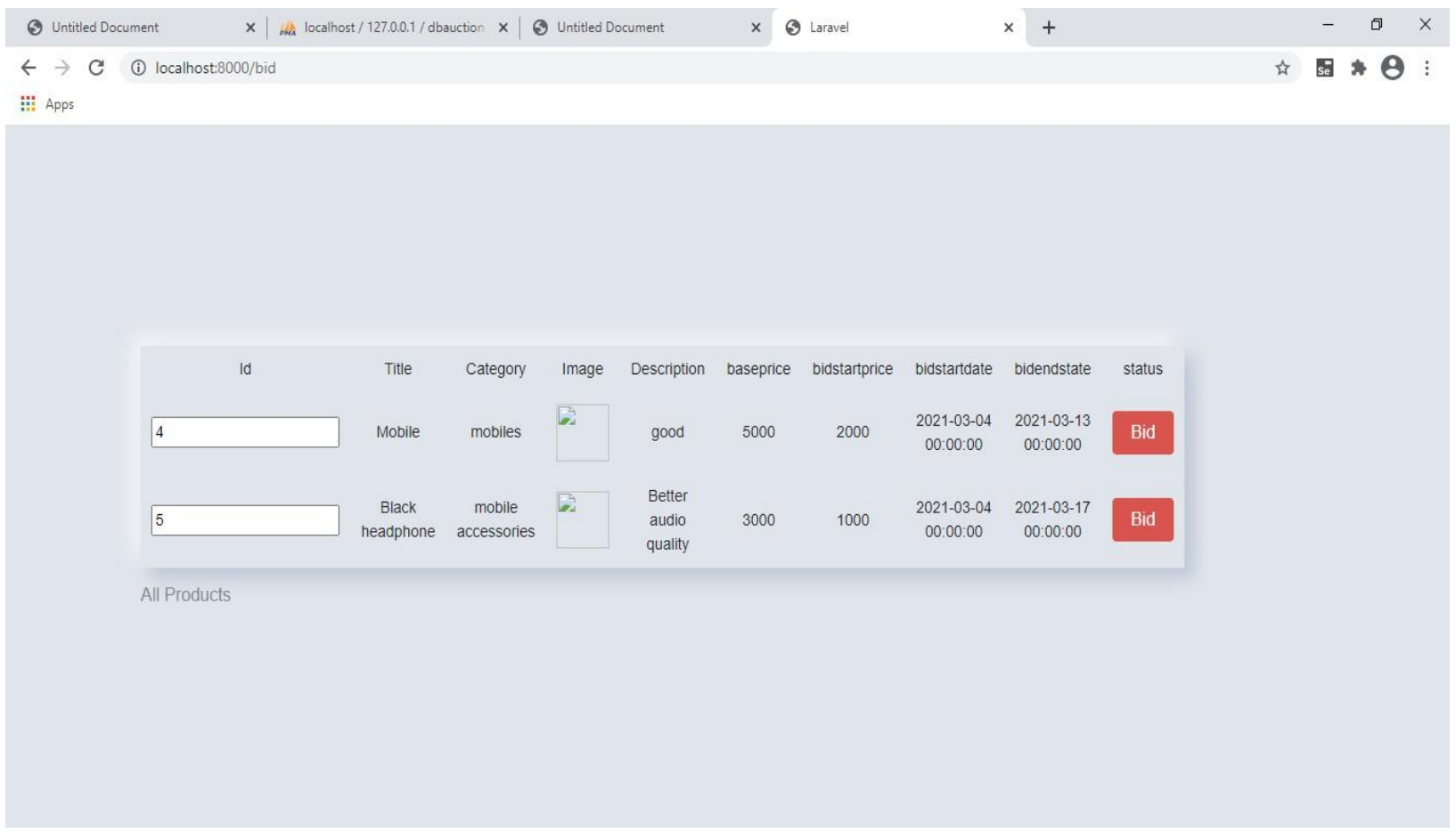

Figure-6 Products available for auction

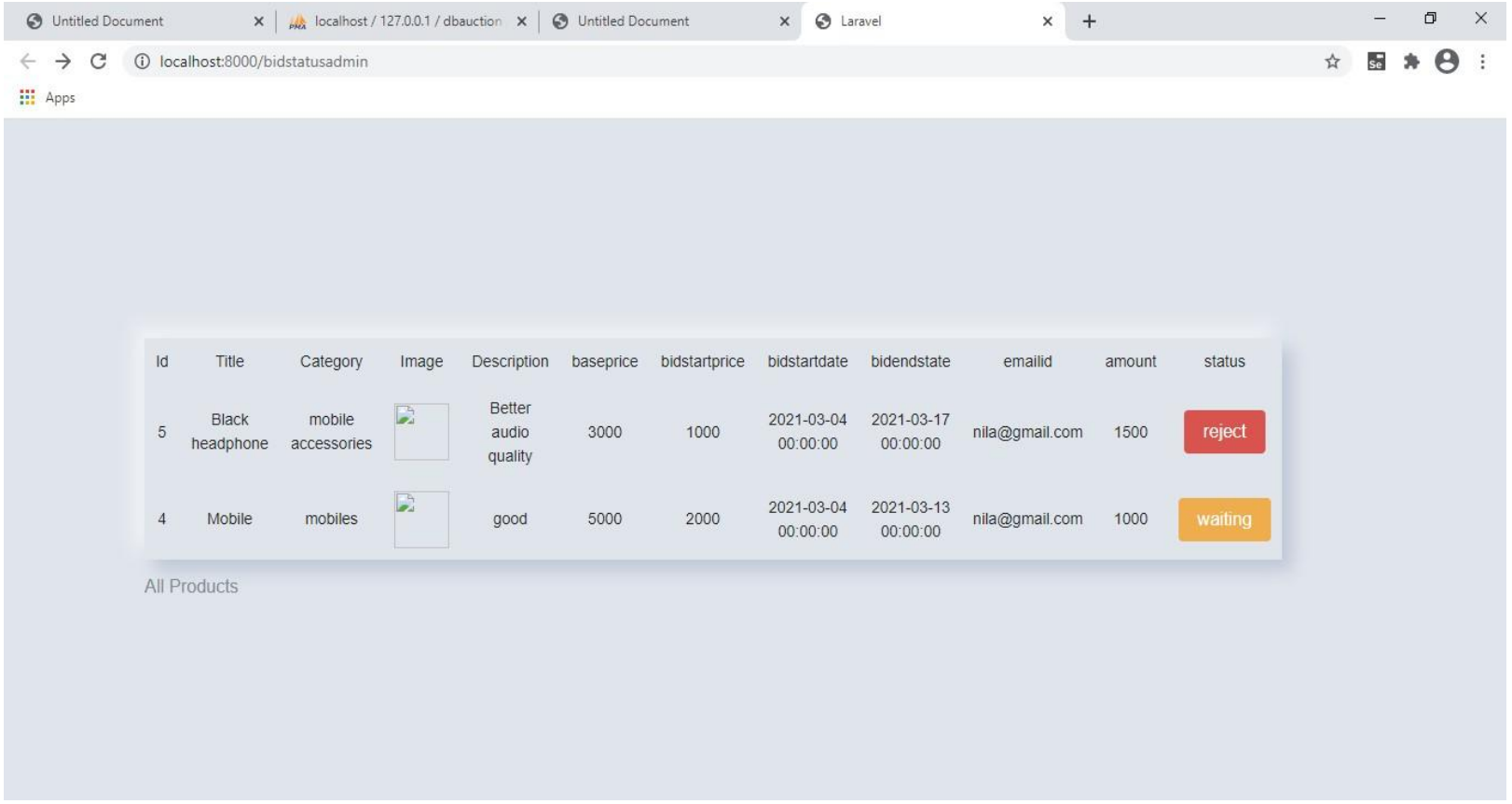

Figure-7 Bidding Status 


\section{CONCLUSION}

Online auction has made the interested bidders from being physically present in auction houses. The auction website provides variety of products online which gives many choices to the bidders to select the product of their interest. The products are placed according to their location.

\section{FUTURE ENHANCEMENT}

Online Auction System has made consumers more effective and efficient in their behaviour and has driven businesses to a new level. Though the buyers can view his status in our website, they are not notified when he won the auction.So further notifications like email and SMS can be made as future enhancements.

\section{REFERENCE}

[1] Manasi Bhamare, Arati Chame, Gaurav More Prof. Amol Rindhe ," Online Auction".

[2] Geetanjali Sawant, Ganesh Bane, Akshay Gurav, Swaraj Pawar, "Survey on Online Auction System".

[3] Nazia Majadi ,Jarrod Trevathan, Neil Bergmann's uAuction: Analysis, Design and Implementation of a Secure Online Auction System

[4] Rashesh G Chothani, Punit R Patel , "A Review of Online Auction and It's Pros and Cons “.

[5] Rodel Balingit, Jarrod Trevathan and Wayne Read, "Analysing Bidding Trends in Online Auctions".

[6] Razon Aldej, Latifa Alfowzan, Reem Alhashem, "Analyzing Designing and Implementing a WebBased Auction online System"(2018).

[7] Chuancheng Ren,"Research and Design of Online Auction System Based on the Campus Network Using UML"(2008). 


\section{Authors}

S.Kokila doing final year MCA in Francis Xavier Engineering College

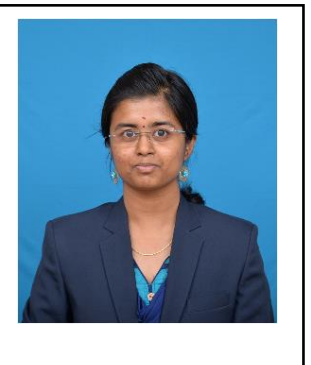

J. Abalin Luther is working as Assistant Professor in the Department of Computer Applications, Francis Xavier Engineering College. She is having teaching experience of 5+ years. Her area of interest is Wireless Sensor networks

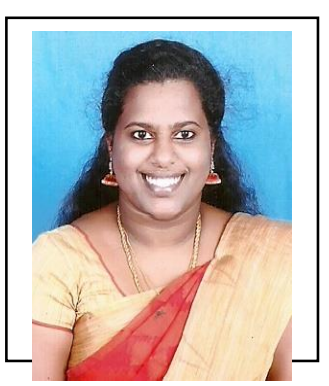

T.Marivijayakumar doing first year MCA in Francis Xavier Engineering College

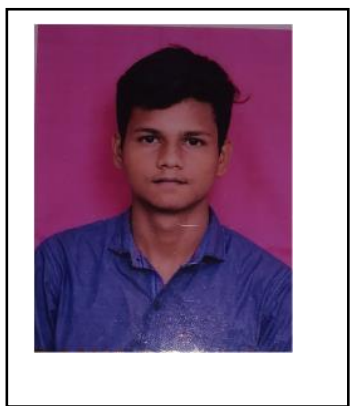

